\title{
Mathematical modeling of the electric spark ignition of the coal-water particle fuel under conditions relevant to the internal combustion engines
}

\author{
Samen Syrodoy ${ }^{1 *}$, Oleg Penyazkov ${ }^{2}$, Mohamad Assad ${ }^{2}$, and Nadegda Gutareva ${ }^{1}$. \\ ${ }^{1}$ National Research Tomsk Polytechnic University, 634050 Tomsk, Russia \\ ${ }^{2}$ Institute of Heat and Mass Transfer, 220000 Minsk, Belarus
}

\begin{abstract}
Annotation. The results of the mathematical simulation of the coal-water fuel particle in the conditions of electric-spark discharge have been given. It has been found that the CWF particle can ignite even in a relatively low $(\mathrm{Tg}<500 \mathrm{~K})$ ambient temperature. It has been shown that the strength of the current and ambient temperature have a significant effect on the characteristics and conditions of ignition.
\end{abstract}

\section{Introduction}

The uncertainty in the energy markets (oil and gas) [1] has significantly increased in the recent years (10-20 years). Their heterogeneous distribution in the different regions of the world leads to an increase in the geopolitical tensions [2,3]. Such a situation creates the conditions for the partial replacement of oil and products of its distillation (fuel oil, gasoline, alcohol, etc.) with the new ecological and effective fuel compositions [4]. Coalwater slurry can be classified to the latter. Coal in contrast to oil is more evenly distributed on the planet and can be a factor in the reduction of the "turbulent" dynamics of the prices for hydrocarbons [5]. Coal, however, is the fuel that is difficult to apply for combustion in the internal combustion engines (ICE). The attempts are known to use solid fuel (coal, wood) for internal combustion engines [6]. The latter attempts have been based on the technology of solid fuel gasification and combustion of synthetic gas obtained in the combustions chambers of the engine. However, these techniques require cumbersome and expensive reactors of the gasifiers [6]. Taking into account the constrained layout of the car, the application of technology of the coal gasification is unlikely.

One of the most promising ways to use coal as a fuel for internal combustion engines is the combustion of coal fuel in coal-water slurry [7]. This technology will allow with the minimal changes in the design of the piston or rotary engine to use coal as the main fuel for the vehicles for different purposes (cars, locomotives, river and sea vessels, etc.) [8-10]. However, so far, the processes of the particles ignition of the water-coal fuel in the conditions corresponding to the combustion chambers of the internal combustion engine while the spark discharge have not been investigated.

*Corresponding author: ssyrodoy@yandex.ru 
It is known that the WCF is a substantially heterogeneous structure, consisting of liquid (water) and solid (coal, organic fuel, metals) components [11]. It should be noted that the ignition of the traditional liquid fuels (gasoline) in the combustion chambers of the internal combustion engine occurs due to a complex radiation-convective heat transfer and electric spark heating. It should be noted that the ignition of the hydrocarbon fuel occurs in the conditions of intensive physico-chemical (thermal decomposition) and phase (evaporation of water) transformations [12]. In the process of dewatering of the coal-water particle changes the electrical resistance of the latter changes, respectively, the intensity of heat release during WCF heating also changes. Taking into account the above we can say that the electric spark ignition of the water-coal fuel particle in the conditions corresponding to the combustion chambers of the internal combustion engine is a complex and still unsolved problem.

The aim of this work is the mathematical modeling of ignition of coal-water fuel particle by heating by an electric spark.

\section{Mathematical model}

When setting the task, it has been assumed that water-coal particle enters the combustion chamber of the internal combustion engines in the inter-electrode space (fig.1.). As a result, the spark discharge it is heated and the water evaporation process is initiated. The evaporation front moves through the surface into the particle. The resulting water vapor is filtered to the external surface of the particle. The water vapors come into thermochemical interaction with carbon coke. Further heating leads to thermal decomposition of the organic part of the fuel and volatile. The latter are filtered on the surface, near which steam-gas mixture is formed having a flammable range with the achievement of the critical values of temperatures and concentrations of fuel.

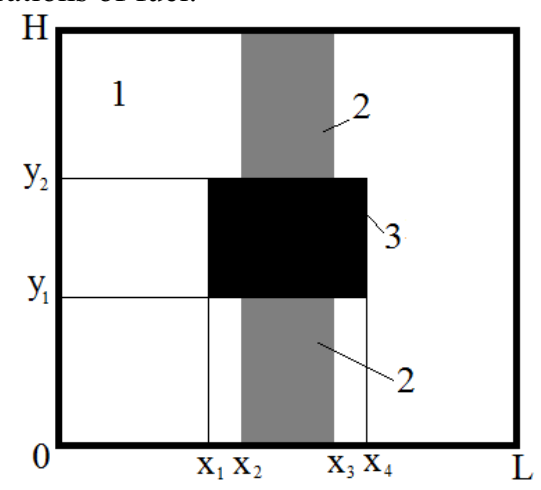

Fig. 1. The scheme of solving the problem. 1 - gas area; 2 - electrodes; 3 - WCF particle.

The mathematical formulation of the problem corresponding to the above physical model includes the system of nonstationary differential equations:

- the energy equation for the WCF particle:

$$
C_{1}(T) \cdot \rho_{1}(T) \cdot \frac{\partial T_{1}}{\partial t}=\frac{\partial}{\partial x}\left[\lambda \cdot \frac{\partial T_{1}}{\partial x}\right]+\frac{\partial}{\partial y}\left[\lambda \cdot \frac{\partial T_{1}}{\partial y}\right]-\frac{Q_{e n} \cdot W_{e w}}{h_{d}} \cdot \delta\left(r_{e a d}\right) \pm \sum_{i=1}^{i=2} Q_{i} \cdot W_{i}-C_{s} \cdot \rho_{s} \cdot\left[U_{s} \cdot \frac{\partial T_{1}}{\partial x}+V_{s} \cdot \frac{\partial T_{1}}{\partial y}\right]
$$

Where: $\quad \sum_{i=1}^{n=2} Q_{i} \cdot W_{i}=Q_{w \rightarrow v o l} \cdot W_{w \rightarrow v o l}+Q_{C+H_{2} O} \cdot W_{C+H_{2} O}+I \cdot R^{2} \cdot \theta\left(x_{1}-x_{2}, y_{1}-y_{2}\right)$

$\delta(\mathrm{x})$ is the Dirac Function. $\theta\left(x_{1}-x_{2}, y_{1}-y_{2}\right)$ - function of Heaviside. The thermophysical characteristics $(\lambda, \mathrm{C}$ and $\rho)$ are determined by the position of the 
evaporation front. The mass rate of evaporation $\left.\left(W_{\text {eva }}\left[\mathrm{kg} / \mathrm{M}^{2} \cdot \mathrm{s}\right)\right]\right)$ has been calculated from the expression [13]:

$$
W_{\text {eva }}=W_{f} \cdot \exp \left(\frac{Q_{w a t} \cdot \mu \cdot\left(T_{w a t}-T_{f}\right)}{R \cdot T_{0} \cdot T_{w a t}}\right)
$$

The temperature distribution in the gas area surrounding the particle is described by the energy equation. The latter takes into account the exothermic effects of the oxidation reactions of the main combustible components by air:

$$
C_{g} \rho_{g} \frac{\partial T_{g}}{\partial t}=\lambda_{g} \cdot\left[\frac{\partial^{2} T_{g}}{\partial x^{2}}+\frac{\partial^{2} T_{g}}{\partial y^{2}}\right]+\sum_{i=1}^{i=4} Q_{i} \cdot W_{i}
$$

Where: $\quad \sum_{i=1}^{n=4} Q_{i} \cdot W_{i}=Q_{C_{4}+O_{2}} \cdot W_{C H_{4}+O_{2}}+Q_{C O+O_{2}} \cdot W_{C O+O_{2}}+Q_{H_{2}+O_{2}} \cdot W_{H_{2}+O_{2}}$

The boundary conditions of the 4 kind have been taken at the boundary of the system partition "WCF particle - gas environment":

$$
\begin{gathered}
\lambda_{1} \frac{\partial T_{1}}{\partial n}=\lambda_{g} \frac{\partial T_{g}}{\partial n} \\
T_{1}(x, y, t)=T_{g}(x, y, t)
\end{gathered}
$$

The temperature distribution in the electrodes is described by the equation:

$$
C_{S} \rho_{S} \frac{\partial T_{S}}{\partial t}=\lambda_{S} \cdot\left[\frac{\partial^{2} T_{S}}{\partial x^{2}}+\frac{\partial^{2} T_{S}}{\partial y^{2}}\right]
$$

The pressure distribution of the mixture of water vapor and products of pyrolysis of the fuel in the particle has been determined from the equation piezo conductivity:

$$
\frac{\partial p}{\partial t}=\chi \cdot\left[\frac{\partial^{2} p}{\partial x^{2}}+\frac{\partial^{2} p}{\partial y^{2}}\right]
$$

The filtration rate of vapor has been determined from the differential expression of Darcy's law:

$$
U_{S}=-\frac{K_{P}}{v} \frac{\partial p}{\partial x} ; \quad V_{S}=-\frac{K_{P}}{v} \frac{\partial p}{\partial y}
$$

When setting the task it is accepted that water vapor enters into endothermic chemical reaction with coal. The reaction rate $\mathrm{C}+\mathrm{H}_{2} \mathrm{O}=\mathrm{CO}+\mathrm{H}_{2}-118.485 \mathrm{MJ} / \mathrm{kg}$ has been calculated from the following expression: 


$$
W_{\mathrm{C}+\mathrm{H}_{2} \mathrm{O}}=k_{\mathrm{C}+\mathrm{H}_{2} \mathrm{O}} \cdot{ }^{c_{\mathrm{H}_{2}} \mathrm{O}} \cdot \rho_{\mathrm{S}} \cdot \exp \left(-\frac{E_{i}}{R \cdot T}\right)
$$

The decomposition of the fuel with the release of volatiles begins when there is the condition on the surface of the particle $T_{\text {sur }} \geq T_{\text {std }}\left(T_{\text {std }}\right.$ - the beginning temperature of thermal decomposition). The process of thermal decomposition is described by the equation of chemical kinetics:

$$
\frac{\partial \eta}{\partial t}=[1-\eta] \cdot k_{w \rightarrow v o l} \cdot \exp \left(-\frac{E_{w \rightarrow v o l}}{R \cdot T}\right)
$$

The rate of pyrolysis has been calculated using the following expression:

$$
W_{i}=[1-\eta] \cdot k_{w \rightarrow v o l} \cdot \rho_{1} \cdot \exp \left(-\frac{E_{w \rightarrow v o l}}{R \cdot T}\right)
$$

The following reactions have been taken into account in the vicinity of the surface of the particle:

$$
\begin{aligned}
& \text { 1. } \mathrm{H}_{2}+0.5 \cdot \mathrm{O}_{2}=\mathrm{H}_{2} \mathrm{O}+141900 \mathrm{~J} / \mathrm{kg} \text {; } \\
& \text { 2. } \mathrm{CO}+0.5 \cdot \mathrm{O}_{2}=\mathrm{CO}_{2}+10090 \mathrm{~J} / \mathrm{kg} \text {; } \\
& \text { 3. } \mathrm{CH}_{4}+\mathrm{O}_{2}=\mathrm{CO}_{2}+\mathrm{H}_{2} \mathrm{O}+55546 \mathrm{~J} / \mathrm{kg} \text {; }
\end{aligned}
$$

The rate of these reactions has been calculated from the mathematical expression of the law of Arrhenius:

$$
W_{i}=k_{i} \cdot c_{i} \cdot\left(1-\sum_{i=1}^{n-1} c_{i}-c_{H_{2} O}+c_{O_{2}}\right) \cdot \rho_{i} \cdot \exp \left(-\frac{E_{i}}{R \cdot T_{g}}\right)
$$

The concentration of the combustible components $\left(\mathrm{H}_{2}, \mathrm{CO}\right.$ and $\left.\mathrm{CH}_{4}\right)$ in the near-wall area has been evaluated by solving the diffusion equation for the corresponding component of the reaction:

$$
\rho_{g} \frac{\partial c_{i}}{\partial t}=D_{i} \cdot \rho_{g}\left[\frac{\partial^{2} c_{i}}{\partial x^{2}}+\frac{\partial^{2} c_{i}}{\partial y^{2}}\right]-W_{i}
$$

The system of equations (1-13) has been solved under the following boundary conditions, and closing ratios:

$$
\begin{gathered}
x_{1}<x<x_{2}, y_{1}<y<y_{2}, T(\mathrm{x}, \mathrm{y}, 0)=T_{0}=298 K, p(x, y, 0)=p_{\text {atm }}, \eta(x, y, 0)=\eta_{0} \\
0<x<x_{\text {out }}, 0<y<y_{\text {out }}, T(x, y, 0)=T_{g}, c_{i}(x, y, 0)=0 .
\end{gathered}
$$




$$
\begin{aligned}
& \left.\frac{\partial^{2} T_{g}}{\partial x^{2}}\right|_{\substack{x=0 ; \\
x=L}}=\left.\frac{\partial^{2} T_{g}}{\partial y^{2}}\right|_{\substack{y=0 ; \\
y=H .}}=0 \\
& \left.\frac{\partial p}{\partial x}\right|_{\substack{x=x_{1} \\
x=x_{2} .}}=\left.\frac{\partial p}{\partial y}\right|_{\substack{y=y_{2} \\
y=y_{1}}} ;=-\frac{v}{K_{P}} u_{S} \\
& \left.p\right|_{\substack{x=x_{\text {out }} \\
x=0}}=p_{\text {atm }} \\
& \left.\frac{\partial C}{\partial x}\right|_{\substack{x=x_{1} ; \\
x=x_{2}}}=\left.\frac{\partial C}{\partial y}\right|_{\substack{y=y_{1} ; \\
y=y_{2}}}=\frac{W_{i} \cdot r_{0}}{\rho_{g} \cdot D_{i}} \\
& \left.\frac{\partial C}{\partial x}\right|_{\substack{x=x_{1} ; \\
x=x_{2} .}}=\left.\frac{\partial C}{\partial y}\right|_{\substack{y=y_{1} ; \\
y=y_{2} .}}=\frac{W_{\text {eva }} \cdot r_{0}}{\rho_{g} \cdot D_{1}} \\
& \left.\frac{\partial^{2} C_{1}}{\partial x^{2}}\right|_{\substack{x=0 \\
x=x_{\text {out }}}}=\left.\frac{\partial^{2} C_{i}}{\partial y^{2}}\right|_{\substack{y=0 \\
y=y_{\text {out }}}}=0
\end{aligned}
$$

The thermal conductivity, heat capacity and density of the wet and "dehydrated" parts of the fuel have been calculated similarly [14]. The formulated problem of mathematical physics has been solved by the finite difference method [15]. The approximation of the equations has been carried out with using the implicit four-point finite difference template. The discretization of the two-dimensional equations has been carried out with using a locally one-dimensional method of Samarskii A.A. [16].

\section{Results and discussion}

Figure 2 shows the dependence of delay time of ignition of the WCF particle on the current strength, obtained by the numerical solution of the system (1)-(19). The ambient temperature $\mathrm{T}_{\mathrm{e}}=300 \mathrm{~K}$. It is clearly seen that even at relatively low ambient temperature $\left(\mathrm{T}_{\mathrm{e}}<600 \mathrm{~K}\right)$ the WCF particles can be ignited stably. The analysis of the results of numerical simulation shows that the current strength has a significant influence on the characteristics and conditions of ignition of the WCF particle. So, when increasing J from 60 to $220 \mathrm{~A}$, the time delay ignition of the fuel particles (diameter $\mathrm{d}=1.5 \cdot 10^{-3} \mathrm{~m}$ ) decreases 2 times (from 0.04 to $0.02 \mathrm{~s}$ ). It may be noted, there is a substantially nonlinear character of the dependences (curves 1-3 of Figure 2). The latter indicates the significant role of the processes of heat and mass transfer occurring together in heavy phases (evaporation of water) and chemical (thermal decomposition, the interaction of water vapor and carbon coke, ignition of volatiles) in the induction period. The analysis of dependences shows, that the linear dimensions of the particle also have a significant impact on the characteristics of ignition. So, at the current of $\mathrm{J}=60 \mathrm{~A}$, the diameter reduction of WCF drops from $\mathrm{d}=1.5 \cdot 10^{-3}$ to $\mathrm{d}=0.5 \cdot 10^{-3} \mathrm{~m}$ (in other words in 3 times) leads to decrease of the ignition delay time from $0.04 \mathrm{~s}$ to $0.01 \mathrm{~s}$ (almost in 4 times).

\section{Conclusion}


According to the results of mathematical modeling it has been established that hydrocarbon particles can ignite even in low temperature $\left(\mathrm{T}_{\mathrm{e}} \approx 300 \mathrm{~K}\right)$. It has been shown that the strength of the current, the spark discharge has a significant influence on the characteristics and conditions of ignition. The increase in $\mathrm{J}$ leads to a significant reduction of delay time of ignition. Taking into account the nature of the curves shown in figure 2 , it is safe to say that the complex of the co-occurring processes of heat and mass transfer plays an essential role in the thermal preparation and ignition of the particles of the coal-water fuel.

According to the results of numerical solution of the system (1)-(19), it has been found that the coal-water particles are ignited stably in the conditions of the combustion chambers of the internal combustion engine. It should be added that the ignition of the fuel particles occurs even at relatively low ambient temperatures $\left(T_{e}<500 \mathrm{~K}\right)$. The latter confirms the possibility of using WCF as the main fuel for internal combustion engines.

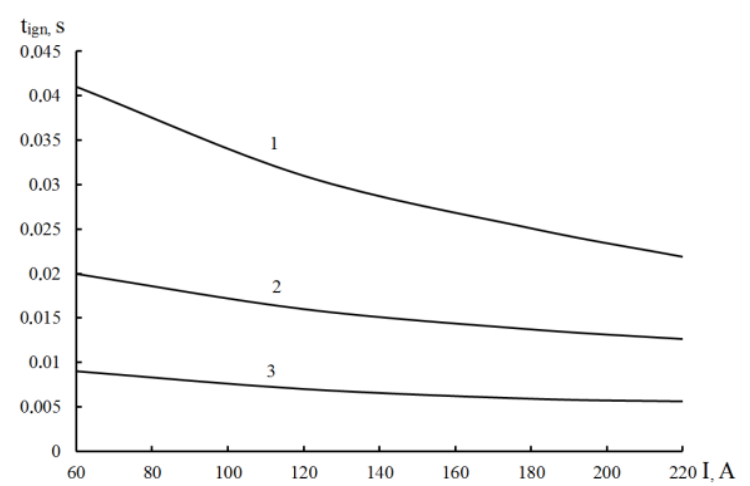

Fig.2. Delay time of ignition of the particle coal-water fuel according to the strength of the current at ambient temperature $\mathrm{T}=300 \mathrm{~K}$. The particle diameter of the WCF:

$1-\mathrm{d}=1,5 \cdot 10^{-3} \mathrm{~m} ; 2-1,0 \cdot 10^{-3} \mathrm{~m} ; 3-0,5 \cdot 10^{-3} \mathrm{~m}$.

This work was supported by the scientific schools grant NSH-7538-2016.8.

\section{References}

1. Y. Weia, X. Guo, Energ. Econ. 56, 88 (2016)

2. Y. Tuzova, F. Qayum, Energ. Policy 90, 140 (2016)

3. Aad Correlje', Coby van der Linde, Energ. Policy 34, 532 (2006)

4. G. Lan, X. Gong, Z. Wang, L. Zhao, Y. Wang, M. Wang, Energy 96, 69 (2016)

5. K. Johnson, B. Mohammed, Energ. Econ. (to be published)

6. A.K. Hossain, P.A. Davies P, Renew. Sust. Energ. Rev. 21, 165 (2013)

7. B. Choongsik, K. Jaeheun, P. Combust. Inst. (to be published)

8. K. Seshadri, J.A. Caton, K.D. Kihn, J. Eng. Gas Turbines Power 114, 515 (1992)

9. K. Wamankar, S. Murugan, Energy 91, 1030 (2015)

10. T. Uzkan, C.E. Horton, J. Eng. for Gas Turbines Power 112, 376 (1990)

11. G. Papachristodoulou, O. Trass, Can. J. Chem. Eng 65, 177 (1987)

12. V.V. Salomatov, G.V. Kuznetsov, S.V. Syrodoy, N.Y. Gutareva, Appl Thermal Eng 107, 10 (2016)

13. Ya.I.Frenkel, Kinetic theory of liquids (Nauka, Leningrad. 1975)

14. V.V. Salomatov, S.V. Syrodoy, N.Y. Gutareva, EPJ Web of Conferences 82, 01037 (2015)

15. A.Zh. Samarskii, Comp. Math. Math. 2 (1962)

16. A.Zh.Samarskii, USSR Comp. Math. Math. 3, 9 (1963) 